\title{
Localizing the "New Snapshot" Textbook; A Study for Intermediate Level Students in Indonesia
}

\author{
Rita Hartati ${ }^{1}$
}

${ }^{1}$ Faculty of Languages and Arts, Universitas Negeri Medan, Indonesia

\begin{tabular}{ll}
\hline \hline ARTICLE INFO & ABSTRACT \\
\hline \hline $\begin{array}{l}\text { Article history: } \\
\text { Received Jan 25, 2020 } \\
\text { Revised Jun 02, 2020 } \\
\text { Accepted Jun 15, 2020 }\end{array}$ & $\begin{array}{l}\text { The purpose of this study is to analyze the "Snapshot" textbook } \\
\text { based on the local characteristics of Indonesian intermediate students. } \\
\text { Therefore, the descriptive analysis method was applied to this study } \\
\text { by using documentation and observation techniques. As a result, five } \\
\text { Keywords: }\end{array}$ \\
$\begin{array}{l}\text { elements need to be adapted based on the local characteristics of } \\
\text { Indonesian students: 1) sociocultural content, 2) language level, 3) } \\
\text { authenticity 4) instruction method, and 5) tests \& exercises. Adapting } \\
\text { the textbook-based local characteristics of students is not simple but } \\
\text { it is important to achieve the learning objectives successfully }\end{array}$
\end{tabular}

English,

Intermediate,

and Indonesian

\section{Clonflict of Interest:}

None

Funding:

None

Corresponding Author: Rita Hartati, Lecturer at English and Literature Department, Faculty of Languages and Arts, Universitas Negeri Medan - Indonesia. Email: ritahartati@unimed.ac.id

Copyright $($ ) Association of Language Teachers in Southeast Asia. All rights reserved

\begin{abstract}
Introductions
The system of education is extremely different in each country even in English Language Teaching (ELT). Talking about the intermediate level, according to the definition in over the world is just the same but in the application, according to the age in each country, there is a significant problem. According to the oxford dictionary, intermediate is having or suitable for a level of knowledge or skill between basic and advanced. (http://oxforddictionaries.com). The other same definition, intermediate is an intermediate English course that is more advanced than a beginners' course but not as difficult as an advanced course. (http://www.definitions.net).
\end{abstract}

From both of the definitions, we know that intermediate is in the middle level of beginners and advanced level. Related to the definition in Indonesia also apply that definition but the application in school if we connect it to the age or grade of students, it is different from England and American rule as in both countries intermediate in age from 11 to 13 years old. (http://dictionary.reverso.net) And in Indonesia particularly in North Sumatera Province, the Intermediate English course level is from 13 to 15 years old. In so doing, the mental of the students will be different according to the age as age between 13 and 15 is adolescent age. In this phase, Maria Montessori said that they are more active, trying to identify themselves, and sensitive to the social environment (Suparmin, 2010:42). Based researcher's experiences, while teaching in Indonesia, adolescents were very active and looking for care from other people such as friends, teachers, and parents. 
For doing that, they did something more negative and they imitated it from each media that they could find such as handbook, magazine, television, and etcetera.

Therefore, it is very important to adapt the textbook based on characteristics of students as in each country, the condition and situation of the students and the environment are extremely different and it is needed to get the goal of education well.

Looking at the "New Snapshot" textbook, the content is very excellent and it is suitable for intermediate students in British, America, Australia, and soon. Otherwise, this textbook is still needed to adapt according to the language ability, local characteristic, and environment of the intermediate students in Indonesia as we see from the textbook that the pictures and names of person, place, institution is still related to the United Kingdom (UK) socio-culture. Besides that, the reading text situation is related to the UK then the test given on the textbook is not related to the National Exam of Indonesian Students.

In Indonesia the level of the students is varied, one way to adapt materials is to rewrite reading texts and grade the language accordingly for different levels. In an ideal world where a teacher has all the time in the world to prepare their classes, this may be the perfect solution. However, the reality is that this sort of adaptation is extremely time-consuming, and not many teachers can go to this length to adapt materials for mixed-level groups. Another problem that can arise with this sort of adaptation is that it can be awkward to give out different texts to different students. There's a danger that they will instantly realize that they have been labeled as a weak or strong student and, in the case of the weaker students, this will no doubt affect their motivation

\section{Theory}

This context is very suitable to the context of Indonesian intermediate students since the textbook will be a suitable text if the textbook adapts to the context of the good textbook. The good textbook is related to Deuri (2012: 26). He said that a good English textbook should have the following characteristics.

Adequate Subject Matter: The subject matter should be based on the psychological needs and interests of students. It should be related to the student's environment. It should have various topics like prose, poetry, story, biography, narration, description, etc. It should be practical utility as well as informative.

Suitable Vocabulary and Structures: The vocabulary should be controlled, properly selected, and graded. The introduction of vocabulary should be progressive within a series of readers. The words and structures should be introduced in a systematic order. The simple meaning should be used as a word or structure if they have more than one meaning. At the end of the textbook, a glossary of difficult words and structures should be given.

Style: The style should be based on the principle of simple to complex. The subject matter should be presented logically. The style should be appealing to the students.

Exercises: There should be a sufficient number of exercises at the end of every lesson. The interactions about the exercises should be brief and clear. The exercises should be well selected and graded. Different types of exercises should be included.

Illustrations: The illustrations should make the subject matter clear. They should be sufficient in number. They should be attractive to the natural color combination. Too many ideas should not be conveyed in one illustration.

Proportion and Order: A lesson should not be very long. There should be a plausible proportion between prose, poetry, story, biography, lesson, etc. Two topics should not be in continuation. The proportion of content and structure should be maintained. There are some technical characteristics which are given by: 1) The paper of the textbook should be white and durable enough. 2) Spacing, margin, and symmetry should be proper. 3) The headings and subheadings should be in a very boil type. 4) A jacket should be added to the cover. 5) The price of the book should be moderate.

Refers to the researcher's experiences and above-mentioned theory, the "New Snapshot" textbook will be adapted based on the technique of adaptation as change (McGrath, 2002). In this term, not for the entire textbook will be changed but some parts of them. The things that we need to adapt according to McDonough and Shaw (2003:86) are methods, language content, subject matter, the balance of skills, progression and grading, cultural content, and image.

\section{Method}

To adapt that textbook to Indonesian intermediate students, the context of adaptation will be implimented that is divided into two parts namely external and internal. External is what we have such as learner characteristics, physical environment, resources, and class size. Then internal is what the materials offer such

SALTeL Vol. 3, No. 2, 2020: $1-7$ 
as choice of topics, skills covered, proficiency level, and grading of exercise (Stevick, 1972).

Therefore, the "New Snapshot" textbook needs to be adapted based on the theory above including sociocultural content or local genuine, language level and content, image, methods, and test or exercise of condition and situation of Indonesian intermediate students.

\section{Result \& Discussion}

\section{Local genuine}

From the textbook, the culture content is related to the United Kingdom such as the persons' name (Jack, Kelly, Adam, Zoe, Ian, and Sarah). These names will be adapted with the Indonesian name like Joko, Andi, Supriadi, Putri, Sri, and Dian. Besides that, the name of a place on the letter text like London is also adapted to Indonesian places like Jakarta. And the other thing is the picture of persons and places are adapted to the pictures of places and persons in Indonesia.

\section{Language level or content}

The language level that is existed in the textbook is very good and suitable to the intermediate students and the grammar and the writing also suitable for the syllabus in Indonesia which explains about first conditional, imperative clause with conjunction or time clause in the future with when/ as soon as. So from the skills according to language level and content is suitable for intermediate students in Indonesia, so no need to change all the textbook, the students' needs are already given clear and easy to understand and it will be easy for the teacher to explain and also easy for the students to understand. About the vocabulary that is given in the textbook is very suitable and can improve the student's knowledge about the new vocabulary that is related to the topics given. About the part of communication or speaking is about to agree and disagree. This topic is also suitable to the syllabus and the explanation is very clear and the practice will be given on group, not in pairs.

\section{Authenticity}

From the textbook, the authenticity of the textbook is good but it is authentic to the UK environment not in the Indonesian environment. In that textbook, the reading text is on BBC reporter Rageh Omaar and the letter text is on the letter of students in London and the situation given is in the UK. So this text is adapted to Indonesian with change the text based on Indonesian reporter and the situation of the letter in Indonesia like in Yogyakarta or Medan city. Look at the text on reading text from the textbook is already good and suitable for students, I will not change the text just a little bit on the name and the situation at the last section with the question why do people do the job? This textbook is giving the BBC reporter but it will be nice and good if I change with Indonesian reporters like TV one Reporter namely Virrisya Debora. The picture is in the appendix.

\section{Instruction Methods}

The method that is applied in the textbook is in pairs. Most of the exercises are doing in pairs. In this level based on the characteristic of Indonesian students at the intermediate level, they are weak in the English language level but they are active and want to show that they can do it well. Because of that, the method that will be applied in this textbook is in-group not in pairs. So the direction is giving in-group so that they can discuss with their friends and they can be active and they can enjoy their studies. Additionally, in that textbook, the students are asking to read first the text and then asking questions but in adaptation in Indonesian intermediate students, I will apply the communicative and contextual teaching-learning. In so doing, I will ask the students first about their experience related to the topic and after that, I ask them to read the reading text so that they can easily understand what is inside of the topic and the reading text.

Indonesian students are mixed ability to one extent or another. Extreme cases, when you have near-native level speakers with beginners, can be very challenging for the teacher. In these cases, it's important to remember that all students will get something out of the class, but not necessarily the same things, and not necessarily what you aim to teach them! For example, beginners may begin to get a grasp of your classroom language whilst the stronger students may begin to be able to put a new tense into use. To handle these cases, the Tips for good classroom management with mixed ability groups will be given as follows: 
Table 1. Adapting materials for mixed ability classes (http://www.teachingenglish.org.uk/)

\begin{tabular}{|c|c|c|}
\hline $\begin{array}{l}\text { Language } \\
\text { Skills }\end{array}$ & $\begin{array}{c}\text { Extension activities for stronger } \\
\text { students }\end{array}$ & Support for weaker students \\
\hline Reading & $\begin{array}{l}\text { Ask early finishers to write new vocab } \\
\text { up on the board with definitions. } \\
\text { Rewrite a part of the text in a different } \\
\text { tense/person. } \\
\text { Write their personal opinion / a summary } \\
\text { of the text. Write questions about the } \\
\text { text. }\end{array}$ & $\begin{array}{l}\text { Pre-teach difficult vocabulary and leave it written } \\
\text { on the board for students to refer to. Use visuals if } \\
\text { possible. } \\
\text { jumbled order, with a few extras. } \\
\text { Draw attention to the title, pictures, etc, and set } \\
\text { the scene beforehand so their mind is on track for } \\
\text { the topic. } \\
\text { Break the text into chunks and give the option of } \\
\text { only reading some of the text. }\end{array}$ \\
\hline Listening & $\begin{array}{l}\text { Give out the tapescript and nominate a } \\
\text { 'vocabulary master' to look up tricky } \\
\text { words or expressions in a dictionary to } \\
\text { then explain to the group. } \\
\text { Focus on the accents or intonation of the } \\
\text { speakers and get students to copy } \\
\text { chunks.sLEPS. If it's a true/false activity, } \\
\text { follow on by asking 'why/why not?) }\end{array}$ & 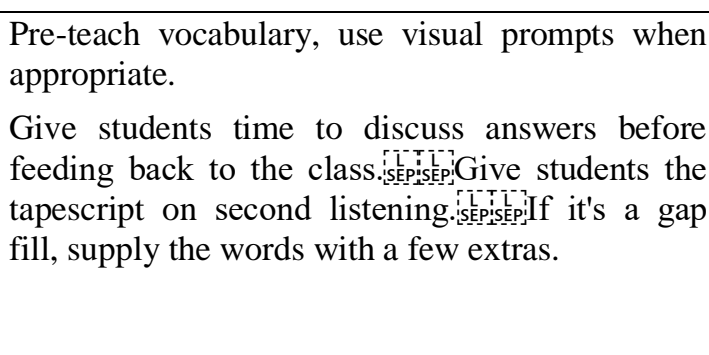 \\
\hline Writing & $\begin{array}{l}\text { Give creative tasks that students can do } \\
\text { at their level. } \\
\text { Indicate mistakes using correction code } \\
\text { to give students a chance to self-correct. } \\
\text { ( } \mathrm{Sp}=\text { spelling, } \mathrm{Gr}=\text { grammar etc.) } \\
\text { Increase the word limit. } \\
\text { Indicate where they could use more } \\
\text { interesting ways of saying something. }\end{array}$ & 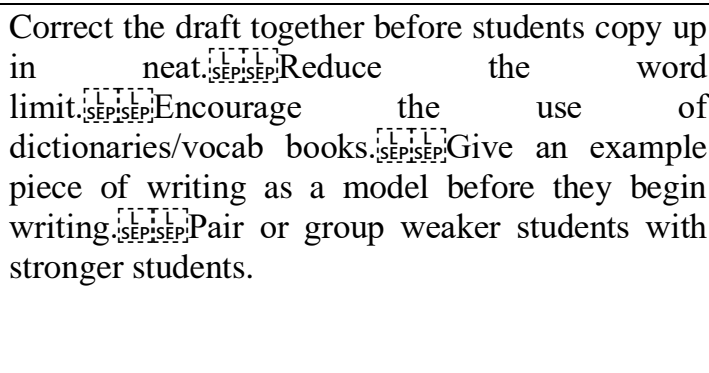 \\
\hline Speaking & $\begin{array}{l}\text { Ask students to justify/defend their } \\
\text { opinions. } \\
\text { Ban easy words like 'nice' to push their } \\
\text { vocab to a higher level.sepseptiset students } \\
\text { to record themselves and self- } \\
\text { correct. } \\
\text { together so they go for it. }\end{array}$ & 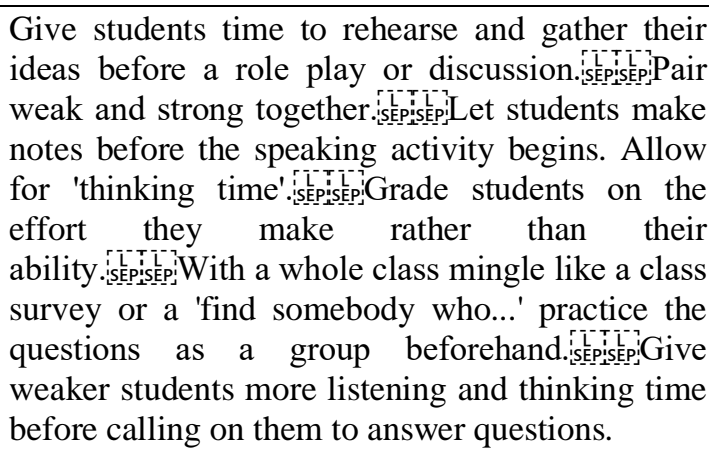 \\
\hline
\end{tabular}

\section{Test or exercise}

The test or exercise given on the textbook is a very good test and exercise but in Indonesia, the test should be related to the national exam (UN) since the end of the study the students will be given the test by the government and this is the important part for them because if they cannot past the test they cannot continue their study to the next level. The style in Indonesian national exam is multiple choice and the in reading text and listening text they will be tested on five main things based on the text that are topic sentence, supporting sentence, implicit meaning, conclusion, and vocabulary used on the text like synonym, antonym or the word order. So, they have to be given the test based on the 5 important things in reading text and listening text. 
From the textbook, the test is not on that side but the test on that textbook is very good and suitable for the students so I will not change the test but I will add the test so that they can improve their ability on that side because they need more exercise and they like to do it on the group.

Those five (5) elements need to adapt the New Snapshot textbook to Indonesian students at the intermediate level. And then I will make the textbook is more simple as the time given for this unit is just 4 hours or in Indonesian just 3 meetings as 4 hours, it means 240 minutes and in Indonesia, one lesson is 40 minutes and one meeting is 2 lesson or 80 minutes so this unit will cover for 3 meeting or 6 lessons. And I will divide the lesson for the students on meeting 1 study about reading skills, on meeting 2 studies about listening and speaking because they can learn it together after that on meeting 3 they will study about writing skill. So the time is given and the unit is matching. So the teacher and the student can get the goal of the study well.

\section{Conclusion}

To sump up, adapting the textbook is complicated but it is important to achieve the learning objectives successfully. Therefore, the New Snapshot textbook is adapted based on the theory about the students' condition and situation, the theory of adaptation, theory of good textbook, and combined with my experience when I was getting the teaching practice in intermediate level in Indonesia. From the theory and the experience, the main things that are needed to adapt are culture content, language content, image, methods, and test or exercise because different countries the 5 items or things are different.

Recommendation to the teacher, headmaster and teacher advisor and etcetera, to adapt the textbook to the students in over the world, we have to consider about the 5 items and the important thing is the condition and situation of the students like their language level such as poor or weak, high or good and maybe advance level. Because this thing will affect all the items that you want to adapt to. And for the government, we hope that government has the political will to facilitate the teacher or textbook advisor to adapt the English Teaching Materials in each of the regents in Indonesia because each of the regents has their own culture, condition, and situation so that the purpose of the education particularly in English Language Teaching can be achieved by the teacher and the student as well. And also the national purpose can be got as well by the government.

\section{References}

Buden, J. (2008). Adapting materials for mixed ability classes in (http://www.teachingenglish.org.uk/) accessed on June, $12^{\text {th }}-2013$

Deuri, C. (2012). An evaluative study of a textbook in English at the higher secondary level. International Journal of Science, Environment and Technology, Vol. 1, No 1, 24-28.

McGrath, I. (2002). Materials Evaluation and Design for Language Teaching Edinburgh Textbooks in Applied Linguistics. Edinburgh: Edinburgh University Press

McDonough, J., and Shaw, C. 2003. Materials and Methods in ELT: A Teacher's Guide. 2nd Publishing. Oxford: Blackwell Publishers.

Stevick, E. W. (1972). Evaluation and adapting language materials. In H. B. Allen \& R. N. Campbell (Eds.), Teaching English as a second language (pp.102-120). New York: McGraw-Hill

Suparmin, M. (2010). Makna psikologi perkembangan peserta didik. Jurnal Ilmiah SPIRIT. ISSN : 14118319 Vol. 10. No. 2. dictionary.reverso.net/english-definition/an\%20intermediate\%20student accessed on June, $10^{\text {th }}$ - 2013 http://oxforddictionaries.com/definition/english/intermediate accessed on June, 10 th -2013 
Appendix 1.

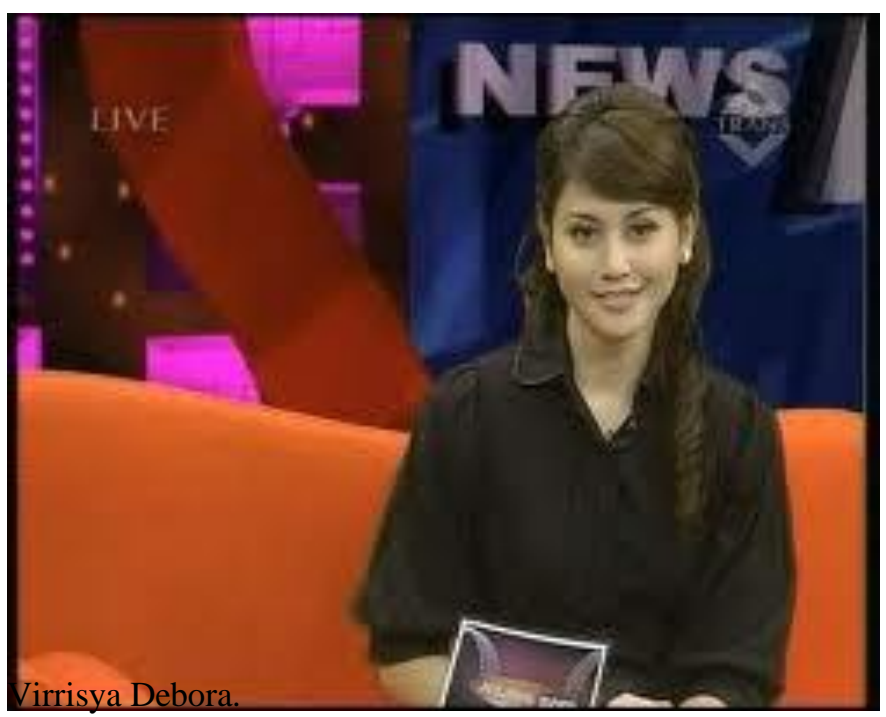

Presenter at TV One Indonesia.

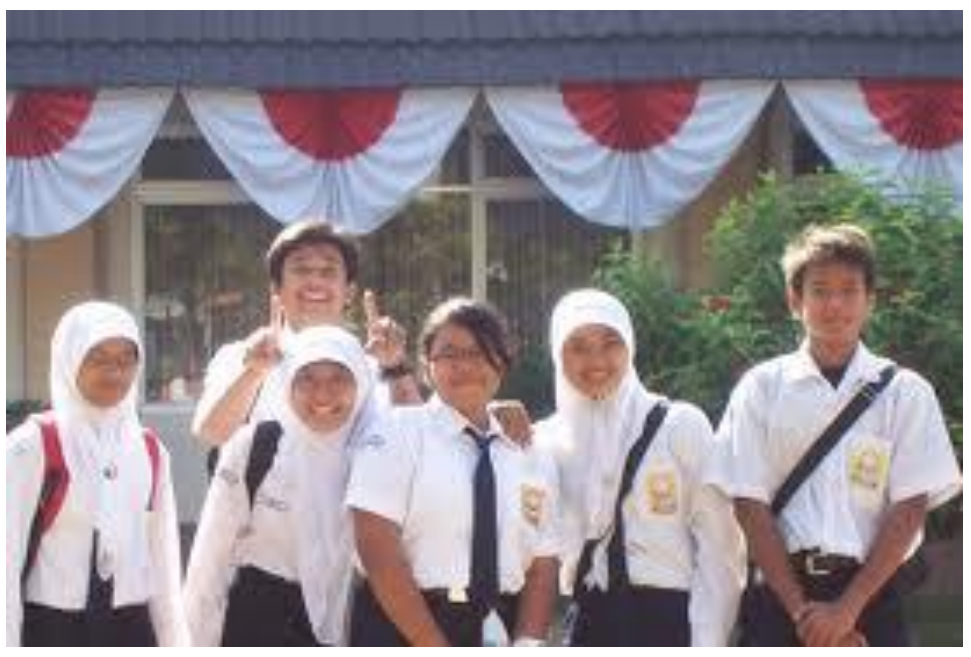

Example of photo that is applied in textbook 
Appendix 2. Example of letter (writing skill)

Jl. Condet No. 43 Kramatjati

Jakarta Timur 13530

November 7, 2012

\section{Dear Imam}

It's been so long I haven't seen your face again. How are you? I hope see your face again, since I saw you last year. I am in holiday right now. It's great.

I spent my school holiday to go camping in Ciremai Mountain. You know, this was our hobby that we admired most. I was getting a nice moment here, you know after studying hard in the school, this was the time to refresh my mind. My camping was accompanied by our friend Sanusi. Did you still remember Sanusi? The little fat man who always carried a big bag. You would never forget that person.

I came here, in the camping land with Cirebon Nature Lovers. It was so fun, we did a lot of great job here. We explored the mountain and cleaned the mountain from the trash. We collected and gathered the trash and brought them to the camping land. In the camping land, we burnt the trash to creat fire. When the fire was lit up, we people were like in a party. We danced, laughed, sang, and laughed. That was a great moment.

I hope your holiday's been going well for you too. My holiday that day would complete if you were there with me and Sanusi. Would you like to meet up some time in the next holiday?

Your besr freind,

P.S. Sanusi says hi. 